\title{
Me sinto de mãos dadas! Um estudo sobre efeitos de comunidade no comportamento online de suas participantes
}

\author{
Talita L. Menezes, Joanna L. Q. Marques, Nazareno F. Andrade
}

${ }^{1}$ Departamento de Engenharia Elétrica e Informática- Universidade Federal de Campina Grande (UFCG)

Cep 58429-900 - Campina Grande - PB - Brazil

\{talita, joannaligia\} @copin.ufcg.edu.br, nazareno@computacao.ufcg.edu.br

\begin{abstract}
The internet - in particular virtual social networks - has been shown to be a democratic tool against sexist discourses and in favor of propagating egalitarian ideals. This article describes a qualitative case study in the community "Vamos Juntas - Campina Grande" about the impact of violence suffered ordinarily by women when socializing in online communities, it is also about the importance of such collaborative spaces in the lives of its members.

Resumo. A internet - em particular redes sociais virtuais - tem se mostrado uma ferramenta democrática no confronto a discursos machistas e na propagação de ideais igualitários. Este artigo descreve um estudo de caso qualitativo na comunidade 'Vamos Juntas? - Campina Grande' sobre o impacto da violência sofrida cotidianamente pelas mulheres na socialização em comunidades online, e sobre a importância de espaços colaborativos como este na vida das suas integrantes.
\end{abstract}

\section{Introdução}

A violência contra a mulher - seja física, psicológica, verbal, sexual, institucional ou moral - se destaca como um componente recorrente do sistema que perpetua o machismo ao longo dos anos, no ambiente online esta situação não é diferente. Segundo relatório da Organização das Nações Unidas ${ }^{1}$, um apanhado em escala global sobre a violência no ciberespaço, $75 \%$ das mulheres que utilizam a internet em todo mundo já sofreram exposição a algum tipo de violência. Mulheres entre 18 e 24 anos são mais suscetíveis a ameaças e perseguições, uma a cada quatro mulheres vivem em países onde estes abusos dificilmente serão punidos e em muitos outros países as mulheres relutam em denunciar estas agressões por medo de repercussões sociais.

A rápida propagação da internet torna ainda mais difícil o trabalho dos mecanismos de controle sociais e jurídicos cabíveis em casos de agressão. $\mathrm{Na}$ era da informação, agressores podem atacar a qualquer momento, em qualquer lugar do mundo. O relatório citado destaca ainda que apesar da grande quantidade de mulheres que passam por essas experiências no ciberespaço, apenas $26 \%$ dos órgãos responsáveis nos países pesquisados estão tomando as medidas apropriadas.

\footnotetext{
${ }^{1}$ Cyber violence against women and girls - http://bit.ly/2mVAbFQ
} 
Apesar dos avanços dos direitos femininos, as memórias sociais e meios de comunicação em geral ainda são marcados pelo discurso patriarcal. Se por um lado, com a mídia tradicional (jornais, novelas, propagandas), estamos fadados a consumir o que o senso comum define por politicamente correto - por vezes um discurso misógino e abusivo, o ciberespaço tem se mostrado como um ambiente democrático e horizontal na propagação de discursos massificadores. Para [Benkler 2006], as listas de e-mail, páginas web, dentre outros meios de discussão compõe plataformas de discursos que estão sendo levadas em consideração na esfera política da democracia. Estas plataformas permitem que qualquer cidadão projete um olhar crítico sobre a realidade e traga sua opinião ao debate público. Não havendo barreiras físicas e geográficas que o impeçam de falar, o sujeito torna-se menos passivo e, a medida que diversos sujeitos trazem suas visões críticas, é possível estabelecer espaços de debate público e político.

A luta contra a situação de violência sofrida diariamente pela mulher vai além de medidas de proteção para coibir a agressão. É necessário que a vítima possa usufruir de um ambiente que conte com suporte jurídico, físico e psicológico. No Brasil, por vezes, este ferramental de apoio é um tanto quanto precário e conta com agentes públicos despreparados, número de delegacias da mulher reduzido, além de delegacias que não funcionam 24 horas. Segundo [Ferreira 2013], o movimento feminista representa uma reação das mulheres à naturalização da violência pelas mesmas, ressalta a importância da internet e seus aparatos como uma ferramenta de divulgação, crítica, reação e diálogo com distintos setores sociais, e o consequente reconhecimento da grande mídia sobre o movimento após a proporção tomada por este no ambiente online.

Este estudo combina observação participante e entrevistas semiestruturadas para examinar o papel de uma comunidade online para o mútuo apoio de mulheres na cidade de Campina Grande - Paraíba, ao longo de oito meses. Através dos dados coletados, nossa análise mostra como a agressão sofrida cotidianamente afeta a socialização feminina em comunidades online, e como o surgimento de um espaço exclusivo às mulheres viabilizou a criação de mecanismos, políticas de acolhimento e apoio recíproco. Investigamos como esses mecanismos e políticas mudaram em conjunto o propósito da comunidade ao longo do tempo, e quais fatores contribuíram para sua permanência ou partida.

\section{Visão da comunidade}

"Vamos Juntas?" foi um movimento nascido a partir de uma experiência de insegurança vivenciada pela jornalista Babi Souza, 24 anos, em uma praça mal iluminada em Porto Alegre (RS) ${ }^{2}$. O momento de vulnerabilidade levou Babi a refletir que uma companhia feminina naquele momento lhe traria conforto e segurança, então por que não levar essa ideia para todas as mulheres que passam por situações parecidas diariamente? Deste episódio nasceu o movimento "Vamos Juntas?", uma iniciativa que propõe interligar mulheres - que se conhecem ou não - em situações de medo ou risco ${ }^{3}$. O movimento -

\footnotetext{
2 "Vamos Juntas?": Conheça o projeto que incentiva as mulheres a andarem juntas para inibir a violência - http://bit.ly/1NK5avd

${ }^{3} \mathrm{O}$ "Vamos Juntas?" - http://bit.ly/2q56Ylz
} 
que atualmente atrai mais de 450 mil fãs em sua página na rede social Facebook ${ }^{4}$ tomou tal proporção que mulheres de diversas cidades brasileiras criaram grupos locais com propósito semelhante.

A iniciativa é um chamado à sororidade, ou seja, um convite baseado na empatia e no companheirismo para que as participantes se unam e se fortaleçam, e obteve atenção positiva na mídia nacional. Em Campina Grande (PB) um grupo local surgiu em meados de junho de 2016 (época que ocorre a festividade de São João em um parque no centro da cidade), a partir da criação de um grupo fechado no Facebook. O grupo surgiu com a intenção de conectar mulheres que precisassem de companhia para ir, voltar ou aproveitar a festividade, que acontece em todas as noites do mês de Junho. A partir de conexões feitas através do grupo do Facebook, as participantes organizaram-se em grupos de WhatsApp por bairro, para que as que morassem mais próximas umas das outras pudessem se ajudar. A ação teve êxito e houveram relatos no grupo do Facebook de mulheres que conseguiram companhia, dividiram o mesmo táxi, pediram ou forneceram carona. Estes relatos talvez tenham fornecido àquele espaço um capital social (credibilidade) inicial necessário para que as integrantes se mantivessem ali e que aquele espaço inspirasse confiança. A partir daquele momento as membras que tinham dúvidas sobre o propósito daquela união de mulheres podiam contar com depoimentos sobre experiências reais vividas e interagir através da nova ferramenta com suas semelhantes, cujo propósito ali era amparo mútuo. Após o término da festividade, os grupos específicos de cada bairro caíram em desuso, enquanto no grupo inicial no Facebook surgiram espontaneamente postagens e comentários sobre os mais variados assuntos.

Hoje o grupo conta com mais de quatro mil integrantes e convida mulheres a ampararem umas às outras, seja fazendo companhia em uma situação de risco ou insegurança, seja compartilhando informações sobre produtos, prestadores de serviços e artigos interessantes, ou até mesmo compartilhando experiências pessoais e realizando atividades em grupo. Dar e pedir indicações sobre médicos, taxistas, advogados e outros prestadores de serviço ou produtos é uma prática recorrente no grupo. De certa forma a utilização deste recurso de indicações traz à tona a confiança que as membras têm no ponto de vista das demais.

Ainda que o recurso "grupo" do Facebook não seja projetado especificamente para as demandas dessa associação de mulheres (fazem falta melhores meios de controle sobre quem entra no grupo, alguma maneira de catalogar post informativos, dentre outras funções), estas se apropriaram desta tecnologia como seu ponto de encontro. Os recursos de postagem, eventos, documentos e enquetes foram moldados à realidade das utilizadoras. Com base na observação outros grupos da mesma rede social, a frequência de interações na "Vamos Juntas?" é alta, diariamente é comum que mais de oito postagens sejam realizadas e discutidas pelas membras.

Ao longo da sua história a comunidade passou por processos de transição e experimentação de diversas arquiteturas de colaboração para tentar suprir suas necessidades. A criação de um ponto de encontro central (grupo no Facebook), a

\footnotetext{
${ }^{4}$ Facebook - http://www.facebook.com
} 
difusão em grupos menores (grupos no WhatsApp) e a retomada deste primeiro local são um exemplo dessas experimentações. Outro recurso disponibilizado pela plataforma do Facebook é a possibilidade de criar documentos compartilhados entre os membros (ficheiros), mas talvez pela dificuldade de encontrar essa funcionalidade na interface gráfica do site e dificuldade de manter o documento organizado, criou-se uma planilha colaborativa em outra plataforma (Google Drive) na tentativa de catalogar melhor as informações disponibilizadas pelas integrantes do grupo às demais.

Regras foram definidas pela moderação à medida que eram necessitadas e adicionadas à postagem fixa no cabeçalho da página do grupo, como por exemplo, evitar postagens repetitivas, postagens de cunho comercial, evitar brigas. Já as normas de conduta social são as que, pelo senso comum, geram uma boa convivência entre pessoas [Lessig 1999], por exemplo, tratar as demais com gentileza e educação. Atualmente a comunidade é administrada por nove mulheres, responsáveis por aceitar novas solicitações de ingresso, mediar conflitos e cuidar para que regras e normas sejam respeitadas.

\subsection{O pesquisador como membro do grupo}

A participação de uma das autoras deste trabalho na "Vamos Juntas? - Campina Grande" se deu logo no início da comunidade, enquanto a outra autora foi adicionada ao grupo pouco antes da realização do presente estudo com a finalidade de observar a dinâmica do espaço.

A experiência da primeira autora a entrar na comunidade está marcada por interações com as postagens realizadas. Apesar de não envolver-se tanto em outros grupos da mesma rede social, seu comportamento nessa comunidade é mais ativo devido ao fato de conhecer pessoalmente várias das integrantes e sentir-se confortável em adentrar nas discussões apresentadas. Ademais, embora durante o estudo as autoras tenham assumido o papel de pesquisadoras, ambas foram ao mesmo tempo participantes do grupo se engajando nas demais atividades do grupo como tal. Essa experiência ao mesmo tempo permite uma visão em primeira pessoa do funcionamento do grupo, e torna necessário o entendimento da existência desse envolvimento durante a análise e interpretação dos resultados.

\section{Questionamentos}

O propósito deste estudo se divide em: i) elucidar como a opressão sofrida no cotidiano feminino afeta a socialização de mulheres em comunidades online, ii) captar o impacto da participação na comunidade "Vamos Juntas? - Campina Grande" em suas membras em relação a outros espaços online. Para isso, foram formuladas as seguintes questões de pesquisa:

QP1: como a situação de violência sofrida no cotidiano feminino afeta a maneira na qual as mulheres interagem e socializam em comunidades online?

QP2: quais as contribuições da presença na comunidade "Vamos Juntas? Campina Grande" na atitude e postura das mulheres em outros ambientes online? 
Entende-se que, a partir da resposta destes questionamentos, será possível oferecer subsídios para a formulação de estratégias que venham a favorecer espaços de colaboração virtual direcionados ao empoderamento de mulheres.

$\mathrm{Na}$ Figura 1 é possível observar um mapeamento entre a participação na comunidade "Vamos Juntas? Campina Grande", os fatores para o empoderamento feminino, o auxílio de ferramentas tecnológicas para a comunidade objeto deste estudo, e a opressão percebida pelas membras. Os relacionamentos expressos na Figura 1 são hipóteses deste trabalho.

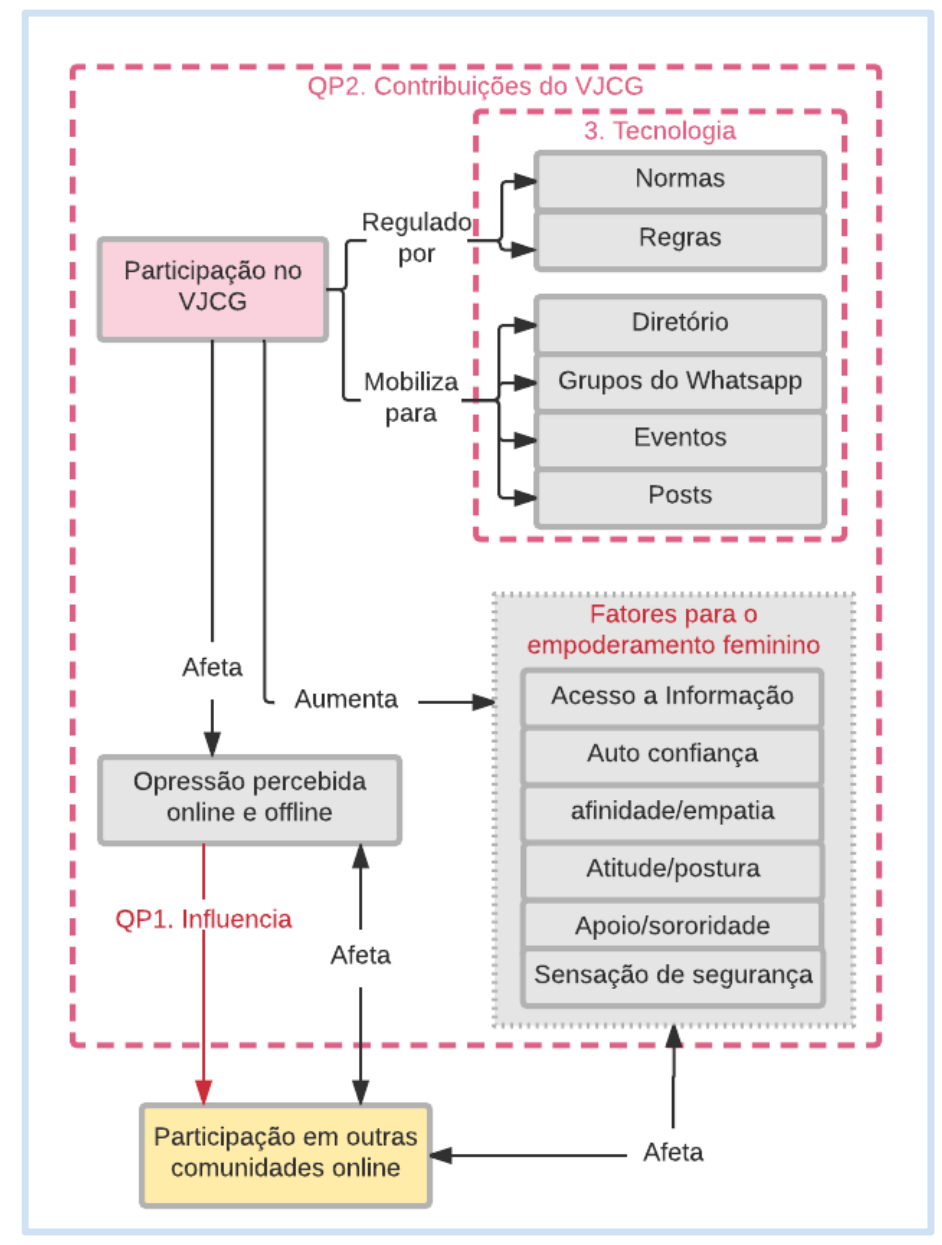

Figura 1 - Participação no "Vamos Juntas? Campina Grande"

\section{Metodologia}

O estudo qualitativo foi realizado por meio de entrevistas semiestruturadas e observação participante em uma comunidade online do Facebook. Para [Minayo 1994] a pesquisa qualitativa não poderia ser realizada sem um trabalho de campo, promovendo a interação do pesquisador com os sujeitos da investigação - fase em que confrontam-se os pressupostos teóricos da pesquisa com a realidade concreta.

Uma possível limitação da utilização de entrevistas semiestruturadas é o fato de que a responsabilidade do sucesso da utilização desta técnica caem integralmente sobre 
o observador (entrevistador), visto que não é requerido nenhum instrumento específico que direcione a observação. Outra limitação está na capacidade de percepção do observador e em como esta pode ser alterada por consequência do seu envolvimento no meio estudado [Haguette 1995].

Esta seção descreve a metodologia do estudo qualitativo e suas etapas. Foram estas: formulação das questões a serem feitas durante as entrevistas, recrutamento e entrevista com as mulheres participantes, e a análise da transcrição das entrevistas.

\subsection{Protocolo de entrevista}

Para que fosse possível coletar dados subjetivos das participações no estudo, optou-se pela entrevista presencial. Nesta fase o empenho foi dirigido à criação de perguntas que pudessem esclarecer os questionamentos da pesquisa, e capturar informações sobre as experiências vividas em ambientes online pelas participantes ${ }^{5}$.

O protocolo de entrevista, composto apenas de perguntas dissertativas, foi dividido em três segmentos: i) questões menos invasivas com a finalidade de estabelecer um primeiro contato e ganhar a confiança da interlocutora (informações triviais e sobre a presença e participação em grupos no ambiente online); ii) introdução e evolução em assuntos mais densos e pessoais (informações sobre pertencimento e participação em comunidades online e na comunidade estudada, situações de violência vivenciadas); iii) encerramento da entrevista e questionamentos mais agradáveis com o objetivo de evitar uma sensação ruim ao finalizar o encontro.

\subsection{Recrutamento das entrevistadas}

O convite para a participação na investigação foi realizado por meio de uma postagem na comunidade do Facebook. A postagem foi realizada no dia 29 de novembro de 2016, 10:16 da manhã e obteve 51 interações (curtidas e comentários).

A interação foi bem recebida pelo grupo. Diferente do esperado, cerca de cinco mulheres se dispuseram a serem entrevistadas de imediato. Em poucas horas todas as participantes das entrevistas já haviam confirmado data, hora e local onde iriam ocorrer as conversas. Esta disponibilidade instantânea reflete com clareza o espírito de cooperação e colaboração presente na comunidade.

Devido ao grande número de participantes dispostas a contribuir com a pesquisa, foi feita uma filtragem de maneira que o grupo selecionado fosse heterogêneo, dentro das possibilidades de escolha. Os critérios utilizados na seleção das entrevistadas foram: volume de interação na comunidade "Vamos Juntas?", área de estudo ou formação e tempo de participação na comunidade. O grupo a ser entrevistado foi composto por oito voluntárias, em sua maioria entre 20 e 28 anos, com diferentes níveis de instrução e em diferentes áreas do conhecimento, em sua maioria eram participantes da comunidade desde o seu início.

\footnotetext{
${ }^{5}$ Roteiro de entrevista - http://bit.ly/2pADSwP
} 


\subsection{Realização das entrevistas}

A realização de todas as entrevistas ocorreu na mesma semana da postagem convite, com data, hora e local definidos pelas interlocutoras. Durante o processo das entrevistas tentou-se manter o ambiente de conversa o mais receptivo e confortável possível, demonstrando segurança ao tocar nos temas mais críticos. As entrevistadas se mostraram abertas aos temas abordados e também confiantes e empolgadas sobre a participação no estudo.

Ao contrário do esperado, assuntos delicados e dolorosos foram tratados com bastante naturalidade. As perguntas foram respondidas com riqueza de detalhes e, ao final da entrevista as questões de encerramento traziam sutileza e descontração supostas.

\subsection{Preparação e exploração dos dados}

Optou-se por fazer uma Análise de Conteúdo do material coletado. Segundo [FrankfortNachmias e Nachmias 1996] esta técnica consiste em uma leitura aprofundada de cada uma das respostas, em que, codificando-se os trechos de cada uma, obtém-se uma ideia sobre o todo [Freitas 2004].

Após a realização das entrevistas todo o material gravado foi convertido em texto escrito por meio do processo de transcrição. O processo foi realizado de maneira manual e, a partir de cada áudio, gerado o documento referente àquela entrevista.

Foi feita uma rápida leitura para criar primeiras impressões e a identificação dos rótulos (tags) que iriam fundamentar a análise dos dados gerados (documentos das entrevistas). Em seguida foi realizada a etapa de exploração do material.

$\mathrm{Na}$ etapa de exploração, os documentos transcritos foram importados em um software para realização da codificação, o MAXQDA Plus 12. Na codificação os dados brutos passaram por uma segunda leitura para uma identificação prévia de códigos, após isso estes códigos foram agregados em categorias relativas às questões de pesquisa, o que permitiu uma descrição das características presentes no conteúdo das entrevistas. $\mathrm{O}$ tipo de codificação utilizado foi a codificação axial, onde serão analisados e reorganizados os conceitos selecionados, extraída uma ideia central e suas ramificações.

Podem ser identificados três temas principais dentre as respostas: exposição dos benefícios providos e elogios ao grupo; movimento, críticas e sugestões; e causas para temer interagir. A seguir, será discutido como cada tópico identificado contribui na elucidação das questões de pesquisa anteriormente formuladas.

\section{Discussão}

As conexões interpessoais geradas por meio do compartilhamento de vivências no grupo pode ser um fator determinante para o sucesso do mesmo, no sentido de motivação dos membros a contar seus casos e também de permanecer ali apoiando, ajudando e tendo cuidado com outras colegas. $\mathrm{O}$ grupo possui uma identidade, um assunto em comum, o que torna as ligações mais fortes [Farzan 2011]. 


\subsection{Barreiras para a socialização online}

Segundos as entrevistas, a baixa autoestima, insegurança e medo de constrangimentos enfrentados por algumas mulheres findam por intimidar sua participação em debates no ambiente do ciberespaço - por vezes em debates onde a voz feminina é (ou deveria ser) protagonista acerca do assunto discutido. Em cada entrevista, pelo menos dois tipos de violências foram citadas por cada participante (assédio e violência verbais, exposição e descredibilização da fala são alguns exemplos).

“Tem um grupo online que eu faço parte que é um grupo $\mathrm{LGBT}^{6}$, [chamado] 'LDRV', e entrou por acaso um homem hétero. Ele entrou no grupo porque alguém adicionou. E tinha uma postagem de uma menina lá, não é amiga (...) mas eu conheci por meio desse grupo... e ele começou a tentar calar ela de todas as formas e dizer que ela tava (sic) equivocada e tipo, não era nem espaço de fala dele mas ele foi super escroto e tentou calar a voz dela de qualquer forma”. (Entrevistada 3, estudante).

“(...) No meu perfil pessoal acontece de alguma vez eu postar alguma coisa, comentar alguma coisa e vir alguém com agressividade, de forma... enfim, a tentar menosprezar a minha luta, a minha palavra, a minha fala. Geralmente, sim, partem de homens, mas existem também algumas mulheres que discordam da minha opinião, mas não discordam de forma passional, discordam de forma agressiva - aí elas transformam o que deveria ser opinião em discurso de ódio e isso acontece diariamente". (Entrevistada 4, modelo e fotógrafa).

Os trechos de entrevistas acima destacam formas de violência percebidas em situações diárias como situações ofensivas e embaraçosas. Ainda que, em algumas entrevistas, tenha havido a presença de mulheres como agressoras, para as entrevistadas os homens são a principal fonte de hostilidade e ofensas.

“(...) Eu tenho certeza que se a comunidade fosse compartilhada com homens também (...) é inerente... eles tentariam sobrepor a voz das mulheres ali”. (Entrevistada 3, estudante).

"Só o fato de ter homens já me submete a possibilidade da gente sofrer alguma opressão, de algum discurso de misoginia, machismo (...)". (Entrevistada 2, estudante).

“(...) Homem não entende, homem não vai saber das dores que a gente tá falando, como é que aquela dor atinge você (...) eu tenho certeza que se tivessem homens a gente não conversaria sobre o que a gente conversa, que são assuntos muito íntimos (...). A logística do grupo não funcionaria tão bem, pelo menos ao meu ver, se tivesse a presença de homens... não só porque eles são os nossos maiores agressores, mas também pela questão da empatia mesmo". (Entrevistada 4, modelo e fotógrafa).

A falta de empatia de outros usuários, principalmente homens, é citada diversas vezes como razão para limitar a própria participação em ambientes online.

\footnotetext{
${ }^{6}$ Acrônimo para Lésbicas, Gays, Bissexuais, Travestis, Transexuais e Transgêneros.
} 
Em um dos relatos foi descrita a situação onde uma mulher postou uma fotografia sua com os seguintes dizeres escritos "Eu não mereço ser estuprada!". Em seguida, uma página conhecida por discurso que se pretende humorístico e é notoriamente machista de grande visibilidade no Facebook compartilhou a mesma fotografia, incluindo um comentário pejorativo fazendo alusão ao fato de que aquela mulher não corria esse risco pois era gorda. Segundo o relato, a proprietária da fotografia tentou, sem sucesso, dialogar com a moderação da página através de comentários a fim de excluir aquela postagem ofensiva. Após uma mobilização, a agredida e sua rede de contatos denunciaram repetidamente a postagem caracterizando-a como abusiva, as denúncias foram acatadas e a própria rede social veio a remover a postagem. A repercussão da situação levou a vítima a mudar a visibilidade da sua foto de modo a estar disponível apenas para seus amigos daquela rede social, e evitar interações de visibilidade pública ali por receio de que a situação pudesse vir a repetirse. Se por um lado a arquitetura da rede social favorece e provê diversos mecanismos para que qualquer pessoa, em qualquer lugar observe, desenvolva seu senso crítico e expresse sua opinião sobre os mais diversos assuntos, por outro favorece a criação de espaços segregadores, onde muitas vezes a única intenção dos grupos é agredir e intimidar usuários cuja opinião seja desaprovada pelos mesmos. A presença de trolls, a dimensão que um discurso em ambientes online pode tomar e o ciberbullying (magoar ou maltratar alguém utilizando tecnologias da informação e de comunicação [Nixon 2014]) também podem ser listados como barreiras na socialização dos integrantes desses ambientes.

[comentário sobre a agressão descrita no parágrafo anterior] "E o pior é que quando eu vi eu pensei que $100 \%$ das pessoas iam cair em cima, que todo mundo ia entender o quanto aquilo era violento, desrespeitoso, e atingiu a liberdade de expressão dela [vítima]... mas quando fui ver os comentários eram coisas escrotas, então eu pude perceber vários sujeitos que compactuavam do pensamento do cara que postou, esculhambando as mulheres, tipo: 'Ah, tu não é mulher!', 'Uma mulher que faz um negócio desse não é uma mulher!'”. (Entrevistada 1, professora e mestranda).

Se nas cidades os indivíduos agrupam-se em subsociedades baseadas em afinidades, interesses ou em laços de vizinhança [Maffesoli 1998], a configuração arquitetural do ciberespaço possibilita tanto a formação desses subgrupos, como simplifica a interação entre eles.

Se considerarmos dois possíveis subgrupos sociais na situação descrita acima, caso ocorresse fora do ambiente virtual, é pouco provável que a moça sozinha se deslocasse geograficamente até o outro grupo para reivindicar seu direito de imagem. Para [Maldonado 2011], em uma situação de agressão online é possível observar três perspectivas: o agressor, o agredido e a plateia. $\mathrm{O}$ agressor, muitas vezes motivado pelo anonimato, pela utilização de um perfil falso ou com o pensamento de que não haverá uma punição para os atos praticados ali, utiliza de qualquer argumento que the pareça cabível para legitimar seu direito de atacar. O agredido, a vítima que está sendo alvo da agressão. E, por fim, a plateia que pode ser dividida em duas, plateia co-autora (que compactua com a ação do agressor) e plateia protetora (que é sensível à situação e apoia 
o agredido). Neste caso, a plateia protetora desempenhou um papel fundamental na situação de agressão, impedindo que fossem feitos mais ataques pelo autor da agressão e pela plateia co-autora. A carência de meios de defesa e encontrando-se em uma situação de isolamento - visto que naquele ambiente a plateia co-autora era maioria - fez com que a vítima procurasse outros meios de contornar a situação (buscar ajuda na sua rede de amigos), o que nem sempre é possível.

“(...) $\mathrm{Na}$ internet, na tela, todo mundo é muito corajoso. (...) E muitas vezes quando você [mulher] se vê cara a cara com o problema você trava. Você não consegue resolver, se sente menor, reprimida. Isso por todo o histórico cultural que nós vivemos". (Entrevistada 3, estudante).

É falado sobre a internalização da violência sofrida, sobre o sentimento de impotência e falta de argumentos durante uma situação hostil. Para [Vieira 2008], em casos de violência doméstica, essa internalização pode levar ao isolamento social da vítima. É possível que um comportamento semelhante, a subtração da voz feminina, também possa ser observado no ambiente online.

Algumas das mulheres entrevistadas sequer tinham ciência de que sofriam algum tipo de violência em certas situações - aquilo já havia se naturalizado na sua rotina.

“Tem coisas que a gente não percebe. Se eu falar: nossa, não tá certo eu andar na rua pra passear com o meu cachorro e se eu escuto um 'psiu' eu não olho, eu baixo a minha cabeça e sigo reto. Um homem no meu lugar olharia, porque se alguém tá te chamando, você olha". (Entrevistada 5, doutoranda).

Apesar da gravidade dos relatos feitos pelas entrevistadas e da preocupação com sua segurança e bem estar, as falas retratam a consciência de que é necessário reclamar seu lugar de fala de direito, um possível bom sinal de que estas mulheres buscam alinhar-se no sentido de reivindicações e pensamentos - visto que, por repetição ao longo da história os discursos patriarcalistas tornaram-se arraigados na cultura de forma a parecerem regulares e justos - de maneira a ecoar esse discurso de percepção também ao longo dos tempos.

\subsection{O ciberativismo no Vamos Juntas e suas contribuições}

Nesta seção foram enfatizados o meios pelos quais a comunidade "Vamos Juntas? Campina Grande" atua no empoderamento e restauração da autoconfiança de suas participantes.

Um ponto importante é a segurança que todas as entrevistadas relataram sentir ao compartilhar relatos e receber indicações de serviços. A noção de que a comunidade é um ambiente seguro para conversar, mesmo tratando-se de uma comunidade online que não utiliza-se de nenhuma ferramenta específica para garantir tal recurso, traz consigo a confiança nas parceiras que fazem a moderação da comunidade e também o conforto de que dificilmente um possível agressor estará à espreita.

"É um local de empoderamento. Quando você se encontra dentro de uma comunidade que você pode falar e não vai ser calada, você se sente empoderada 
de falar em outros meios de comunicação e até nas relações pessoais do dia a dia você vê que você pode ter voz". (Entrevistada 3, estudante)".

Uma das regras do grupo é a expressa proibição de homens ali. As participantes julgam esse fator como indispensável para a manutenção da segurança daquele espaço e parece ser considerado um sinal de limite muito claro dentro da comunidade. A delimitação de regras contribui com o comprometimento de participantes no grupo [Farzan 2011].

O auxílio na percepção de que uma situação vivenciada é uma situação de violência foi um dos tópicos mais citados durante as entrevistas. Ter consciência de que uma situação, até então tida como normal ou corriqueira, não é tão natural assim permite à mulher defender-se e alertar outras para que também façam o mesmo. Atitudes entranhadas na cultura e no dia-a-dia podem passar despercebidas como formas de violência e opressão. A partir dessa percepção e conhecimento das situações pode surgir a mudança de comportamento tanto da mulher, conhecedora dos seus direitos, como também do homem, que saberá que atitudes como aquela não serão mais toleradas.

“A gente também tem que educar os homens, vamos dizer, porque são os homens que repreendem os outros. É como se um machista ele não vai ouvir a gente, mas ele vai ouvir os outros homens. Então as redes sociais serviram não só para a gente mas para outros homens entenderem também o que a gente passa e hoje em dia eu sinto um suporte também por outros homens, não só por mulheres". (Entrevistada 5, doutoranda).

"Muitas opressões eu descubro por causa das redes sociais e meu comportamento muda frente às situações, frente aos homens, frente às mulheres". (Entrevistada 5, doutoranda).

O sentimento de comunidade presente transmite a sensação de estar sempre acompanhada fortalece as ideias de que: ninguém ali está só e ninguém ali é rival, e em uma situação de necessidade alguém oferecerá suporte.

“A gente sempre vai amadurecendo com as coisas, né? Eu também nem atentava para o quanto a gente [mulheres] é desunida, e o quanto que isso nos enfraquece (...)". (Entrevistada 1, professora e mestranda).

"Me sinto de mãos dadas. Pois eu acho que é isso que as mulheres precisam, elas precisam dar as mãos diante de toda a opressão que a gente vê por aí. A gente vê que tudo que conseguimos até agora foi porque as mulheres se uniram para lutar contra as experiências de perversão que a gente enfrenta cotidianamente". (Entrevistada 2, estudante).

"Meu comportamento muda porque eu sei que eu não estou sozinha!". (Entrevistada 5, doutoranda).

Em um ambiente onde a palavra de ordem é sororidade, as entrevistadas relataram situações onde as mulheres mais confiantes e que estão por mais tempo em contato com as ideias suportadas pelo grupo ajudam as demais a perceber e valorizar seu poder, e nesse ciclo novas gerações de mulheres que vão chegando e as demais 
permanecendo. Segundo [Drentea \& Moren-Cross 2005], o que acontece com grupos semelhantes ao "Vamos Juntas? - Campina Grande" é mútuo o oferecimento de suporte emocional e estrutural no que diz respeito a situações de agressão sofrida, indicações de serviços que outras já tenham utilizado, desabafos pessoais, companhia em momentos de necessidade, e qualquer outro assunto que possa surgir. De certa maneira estas mulheres estão conectadas através do relato de suas experiências ao grupo.

"Acho que o grupo não é assunto de meninas, é assunto de pessoas que, apesar de estar em maior número, enfrentam problemas por minoria.., e a gente discute tudo lá dentro ...". (Entrevistada 5, doutoranda).

“(...) É ótimo ter um grupo onde você se sinta segura para desabafar sobre qualquer coisa, seja do assunto mais sério, suas experiências mais difíceis e dolorosas, até falar sobre o que a gente fala: cabelo, maquiagem e outras bobagens". (Entrevistada 4, modelo e fotógrafa).

Outro ponto relevante tocado durante as conversas foram sugestões e críticas ao grupo, com o objetivo de tornar a comunidade um ambiente ainda mais voltado a assuntos pertinentes à realidade feminina. Postagens demasiado individualistas ou sobre venda de produtos foram criticadas, com a justificativa de que isso não seria o cerne do grupo. Ainda que possibilitadas de realizar tais críticas diretamente no grupo, as mulheres concordaram de que se uma postagem é realizada, então há em alguma mulher a necessidade de falar sobre aquilo e que todas têm consciência de que aquele ambiente deve ser mantido com zelo. Assim, os conflitos, aparentemente, são sobrepostos pelo ideal do grupo.

"Ainda tem muito individualismo. Poderíamos fazer coisas mais coletivas, mais conjuntas... tipo: 'O que você tá passando?' 'Quem tá precisando de alguma coisa?' Ter mais esse espírito coletivo. (...) Tem que voltar mais para o tratamento que a sociedade tem com a mulher". (Entrevistada 3, estudante).

O espaço, que teve início como uma ferramenta para conseguir caronas durante uma festividade, evoluiu ao ponto de tornar-se um refúgio às suas integrantes. Para [Oldenburg 1989], um espaço com essa característica pode ser chamado Third Place, onde é possível conversar sobre assuntos mais delicados ou simples banalidades. Esse processo de evolução é continuado a partir do momento que ocorrem novas apropriações de tecnologias para o cumprimento de necessidades, que são definidas ou modificadas regras, de maneira geral, que pode-se perceber registro de vida naquele lugar.

Comentários elogiosos e de agradecimento também surgiram durante as entrevistas. Foi sugerido a criação um encontro entre as mulheres do grupo e a extensão do trabalho dentro da comunidade online para espaços reais.

"Eu acho que tem que ter uma coisa de sair do virtual e se encontrar mesmo, mas pessoalmente (...) Porque eu mesmo que sou tímida, conhecendo as pessoas pessoalmente, talvez eu interagisse mais (...)”. (Entrevistada 2, estudante). 
"Quem sabe pensar em uma ONG para mulheres, fazer palestras nas comunidades periféricas... fazer essa mesma entrevista com algumas mulheres da comunidade periférica". (Entrevistada 1, professora e mestranda).

O que se percebeu foi que este senso comum sobre os obstáculos enfrentados pelas mulheres, finda por despertar em cada uma a motivação e atitude de socorrer outra mulher quando esta se encontre em um cenário vulnerável. O grupo, de fato, representa um lugar seguro para a livre expressão das mulheres, ao mesmo tempo que provê conhecimento e suporte para uma mudança de postura na própria comunidade e em outros ambientes na rede. A clareza de propósito, limites e atributos da comunidade quanto unidade, permite o comprometimento e conexão daquelas mulheres através de uma causa [Farzan 2011].

\section{Conclusão}

Por meio deste estudo buscou-se destacar como a violência enfrentada diariamente pelas mulheres se estende ao ciberespaço, afetando a socialização e interação em ambientes online. Buscou-se também entender como a participação e o envolvimento na comunidade "Vamos Juntas? Campina Grande" contribui na mudança de atitude e posicionamento dessas mulheres em outros espaços de interação na rede.

Durante o processo de entrevista, diversos tipos de violência foram destacadas, como por exemplo, o assédio e agressões verbais, exposição, descredibilização da fala. Em decorrência disso é gerado um sentimento de insegurança, baixa autoestima e timidez frente ao relacionamento social no ciberespaço. É importante ter em mente a ideia de que o que é realizado e discutido no mundo virtual acontece fora dele como uma mudança de pensamento e de comportamento. A partir disso é possível refletir sobre como as atitudes no ambiente virtual são de extrema importância para nossa convivência enquanto sociedade.

Para [Rangel 2011] o papel exercido pela imprensa nos primeiros momentos do movimento feminista no Brasil hoje é representado pela internet. Frente à realidade apresentada, é necessário ampliar a discussão acerca das experiências femininas tanto de opressão e violência, como também de vivências e relatos diversos, para outros meios de comunicação, reconhecendo a riqueza de possibilidades e benefícios que ferramentas online podem oferecer aos movimentos sociais.

As principais contribuições deste trabalho atestam as hipóteses levantadas anteriormente: a participação na referida comunidade contribuiu positivamente no aspecto de empoderamento (percepção das agressões sofridas, busca de apoio, suporte emocional) e mudança de atitude e pensamento de suas integrantes.

Futuramente, espera-se utilizar resultados provenientes de postagens da comunidade estudada para a proposição de um estudo com métodos mistos com a finalidade de complementar os resultados apresentados neste artigo.

\section{Agradecimentos}


Agradecemos às participantes das entrevistas por sua colaboração e às instituições CAPES e Universidade Federal de Campina Grande pelo suporte na realização desta pesquisa.

\section{Referências}

Bardin, L. (1996) "L’analyse de contenu", PUF, 8eme Edition, Paris.

Benkler, Yochai. (2006) "The wealth of networks: how social production transforms markets and freedom", Yale University Press New Haven.

Drentea, P., \& Moren-Cross, J.L. (2005) "Social capital and social support on the web: The case of an Internet mother site", Sociology of Health and Illness, 27(7), p. 920943.

Farzan, R., Dabbish, L., Kraut, R., Postmes, T. (2011) "Increasing Commitment to Online Communities by Designing for Social Presence", CMU, Human-Computer Interaction Institute, School of Computer Science, Carnegie Mellon University Research Showcase.

Ferreira, G. de S. (2013) "Feminismo e redes sociais na Marcha das Vadias no Brasil", Revista Ártemis, Vol. XV nº 1, p. 33-43, ISSN: 2316 - 525.

Frankfort-Nachmias, C \& Nachmias, D. (1996) "Research Methods in The Social Sciences", St. Martin's Press, New York.

Freitas, H. (2004) “Técnica inovadora para análise de dados qualitativos”, Porto Alegre: I SBSI - Simpósio Brasileiro de Sistemas de Informação, PUCRS-UFRGS UNISINOSUCS, p. 205-212.

Haguette, T.M.F. (1995) "Metodologias qualitativas na sociologia", Vozes, 4ed, Petrópolis.

Lawrence L. (1999) "Code and Other Laws of Cyberspace”, Basic Books, p 297.

Maffesoli, M. (1998) "O Tempo das Tribos: O declínio do individualismo nas sociedades de massa", Forense Universitária, Rio de Janeiro.

Maldonado, M. T. (2011) "Bullying e cyberbullying: o que fazemos com o que fazem conosco", Editora Moderna, São Paulo.

Minayo, M.C. de S. (1994) "O desafio do conhecimento: pesquisa qualitativa em saúde”, São Paulo: Hucitec/Abrasco, 3.ed.

Oldenburg, Ray. (1989) “The Great Good Place”, Paragon House, 3ed, New York.

Radin, P. (2006) “'To me, it's my life:' Medical communication, trust, and activism in cyberspace", Social Science and Medicine, 62(3), p. 591-601.

Rangel, L. de A.S. (2011) 'Feminismo ideal e sadio': os discursos feministas nas vozes das mulheres intelectuais capixabas Vitória/ES (1924 a 1934)”, 268 f. Dissertação (Mestrado em História) - Universidade Federal do Espírito Santo, Centro de Ciências Humanas e Naturais. 
Vieira L.J.E.S., Pordeus A.M.J., Ferreira R.C., Moreira D.P., Maia PB, Saviolli K.C. "Fatores de Risco para Violência Contra a Mulher no Contexto Doméstico e Coletivo", Saúde Soc., p. 113-125. 